\title{
NETWORKS AND EFFECTIVENESS IN WORK TEAMS: THE IMPACT OF DIVERSITY
}

\section{IE Working Paper $\quad$ C08-107-I 09 - 02 - 2005}

Margarita Mayo

Instituto de Empresa

María de Molina 12, $5^{a}$ planta

28006 Madrid

margarita.mayo@ie.edu
Juan Carlos Pastor

Instituto de Empresa

María de Molina 12, $5^{\mathrm{a}}$ planta

28006 Madrid

juan.pastor@ie.edu

\begin{abstract}
This paper examine the role of social networks as mediating factors in the relationship between diversity and work team effectiveness. These effects were tested with a sample of 71 organizational teams. Results show that the degree of diversity in a team influences the density and centralization of the communication network. In turn, network density and centralization affect work team outcomes. Results are discussed in terms of their theoretical significance for network and diversity theory.
\end{abstract}

This research was funded in part by a grant from the SHRM Foundation. The interpretations, conclusions, and recommendations, however, are those of the author, and do not necessarily represent those of the Foundation. This research has also been funded in part by a grant from the Programa Nacional de Investigación Científica, Desarrollo e Innovación Tecnológica del Ministerio de Ciencia y Tecnología of Spain, reference: SEC2002-02868. We would like to thank Brian Becker and Michael Farrell for their insightful suggestions and advice on earlier drafts of this paper. 



\section{INTRODUCTION}

The increasing diversity of the workforce and the popularity of teamwork have highlighted the need to better understand and manage the potential advantages and challenges confronting heterogeneous work groups. However, our knowledge of the implications of diversity for team process and effectiveness is limited and dispersed. Scholars are generally divided between those who view diversity as a learning opportunity and those who worry about coordination challenges and personal conflicts when people from different backgrounds work together (see Milliken and Martins, 1996; Williams and O’Reilly, 1998). On the opportunity side, proponents of diversity claim that diverse teams yield creative and effective solutions because of the variety of cognitive resources available within the team. On the other side, scholars who view diversity through the social categorization lens argue that differences among group members give rise to biases in favor of others who are similar in social categories and in detriment of dissimilar others, resulting in less effective group interaction.

Empirical research has reflected the variance found in the theoretical literature. Studies have shown that diverse groups are more likely to be creative, to embrace change, and to reach high quality decisions (e.g., Weiserman and Bantel, 1992; Watson, Kumar, and Michaelsen, 1993; Jehn, Northcraft, and Neale, 1999). At the same time, heterogeneous groups are less socially integrated and attain higher turnover rates (O’Reilly, Caldwell, \& Barnett, 1989; Zenger \& Lawrence, 1989; Jackson, Brett, Sessa, Cooper, Julin, 1991). Most researchers agree that the advantages of diversity potentially exist but that they will only manifest under certain conditions and Williams and O'Reilly (1998, p.98) suggest that the key question becomes when the learning and creative benefits of diversity outweigh the difficulties which result from potential conflict and coordination problems.

Diversity researchers have attempted to solve these apparent contradictory effects by looking at contingencies and mediating processes to understand the relationship between diversity and outcomes. Regarding the contingencies, some studies have found that diversity provides more benefits for creative task (e.g., Jehn, Northcraft, and Neale, 1999; Polzer, Milton, and Swann, 2002), under collectivistic cultures (Chatman, Polzer, Barsade and Neale, 1998) and as team members increase their familiarity with one another (Harrison, Price, and Bell, 1998; Watson, Kumar and Michaelsen, 1993). A second line of research has focused on opening what Barbara Lawrence (1997) has referred to as the "black box" of demography. It is commonly accepted that the uncovering of the key mediating processes between diversity and group outcomes is critical to understand the effects of diversity on organizational teams.

Recently, however, the debate regarding diversity and performance has been reframed in terms of social networks (Mayo, 1999; Reagans and Zuckerman, 2001). In this view, communication networks are considered key mediating factors that relate group composition to group outcomes. The composition of the group would shape the configuration of the network, which in turn will have an effect on team outcomes. A social network paradigm has great potential to shed light on this area. There are several findings underscoring the benefits of using a social network perspective to understand the effects of group diversity on performance.

First, diversity theory suggests that team behaviors are critical mediating variables through which diversity influences team effectiveness. This assertion implies that heterogeneous 
teams outperform, or underperform, homogeneous groups because people act differently in this contexts. Heterogeneous and homogeneous groups differ in how members behave toward one another within the team, resulting in idiosyncratic patterns of group interaction or social structures. It is the pattern of relationships that members of heterogeneous establish that can make the difference in team performance. The relational approach provided by the social network perspective seems appropriate to study group diversity.

Second, research indicates that one of the main problems for members of diverse teams is that they spend either too much time engaging in conflicts and clearing up misunderstandings or too little time interacting with other members that different from themselves. Social network tools and methods are designed to uncover hidden patterns of relationships within the team and they can shed light on these communication processes.

Third, the social network approach provides the necessary tools for conceptualizing and measuring important aspects of the communication structure that emerges at the level of team as a whole. While, most research studies in this area have focused on individuals' behaviors that are then aggregated at the group level, social network concepts and methods allow for the operational conceptualization of individuals' communication at the level of team-as-wholes (Jackson, et al., 1995). Moreover, a social network perspective is consistent with the principles of small group theories (e.g., McGrath, 1984). According to these theories, social systems, such as work teams, are viewed as patterned interaction (e.g., Monge and Eisenberg, 1987; Ibarra and Andrews, 1993), and network variables and methods are specifically designed to capture the actual interaction pattern that emerge in the group. Therefore, network methods and techniques provide a more adequate conceptualization of team communication than traditional aggregation methods.

In this paper, we seek to uncover some of the team network parameters mediating the relationship between team composition and team effectiveness. While previous literature has began opening the black box of diversity, there is a lack of studies that focuses on team behaviors as a true property of the team. We recast the diversity-effectiveness debate in terms of social networks that allows us to capture whole-patterns of relationships that emerge as team members exchange information and develop stable patterns of interaction within the team.

\section{A Social Network Perspective on Small Work Groups}

A social network is a routine pattern of interpersonal contacts that can be identified as group members exchange information (Farace et al., 1977; Monge \& Eisenberg, 1987). The basic components of a social network are nodes and ties. Nodes could represent individuals, groups, organizations, cities or even countries. Ties usually represent relationships of any kind among nodes. When work groups are viewed through a social network lenses, the nodes refer to individual team members and the ties represent relationships among group members. The link or tie is the basic building block of the social network. A link is not the property of any single individual; rather, it is a relational entity that exists only if two individuals are considered together. The content of this relation defines the nature of the network. 
Consistent with the literature in this area (e.g., Danowski, 1980; Ibarra and Andrews, 1993; Krackhardt and Porter, 1986), we conceptualize social networks as patterns of interpersonal behaviors that can be identified as members of a work team exchange task-related and relation-oriented communication. A task network develops around work-role performance and is directly associated with the prescribed objectives of the task. A friendship network is defined as organizational members' exchanging personal information and developing close friendships.

The ties among team members can be described along two dimensions: strength and symmetry. The strength or intensity of the link refers to the frequency with which the two individuals exchange information or influence. For example, a strong link between Person $A$ and Person B exists if A interacts or exchanges information with B more than five times a week; a weak tie exists if A does so only once a month. The definition of a strong link depends, to a great extent, on the average expectation for that type of exchange in that particular social system. For example, in small work teams the communication network often presents intense links among all possible pairs and differences among the links are usually given by the differences in the frequency/intensity of the interaction (it is rare to find some one who does not interact with the other members of a team with five or six members). Symmetry refers to the extent to which the relationship is bi-directional. This is an important feature of ties in networks of influence, because these relations tend to be asymmetrical. That is, the fact that $\mathrm{A}$ influences $\mathrm{B}$ does not necessarily mean that $\mathrm{B}$ will influence $\mathrm{A}$. A mean average of the frequency of interaction reported by the two members is usually obtained as an indication of their degree of communication.

\section{Levels of Analysis in Social Networks}

An important issue in network research is the level of analysis of the network. Social networks can be described at three different levels: From the perspective of their members (individual level), the links (dyadic level), or the properties of the whole network (whole network level). Most research on social networks at the intra-organizational level has focused on individual and dyadic network concepts. First, at the individual level, a common way to describe individuals' position in the network is individuals' network centrality. Network centrality refers to individuals' prominence in the social system. Several measures of centrality capture different properties of individuals' position in the overall social structure. The three most popular measures are degree, closeness, and between ness centrality (see Freeman, 1979; Borgatti et al., 1992). There is large literature at the individual level of analysis using the various centrality measures as they relate to power (Brass, 1984; Burkhardt \& Brass, 1990), satisfaction (Roberts \& O’Reilly, 1979), or leadership (Leavitt, 1951). Second, the ties between any two members of the network are usually described in terms of network proximity. The two most popular measures of dyadic relationships between any two individuals are network proximity and structural equivalence. Studies at the dyadic level of analysis have focused on the question of network proximity and similarity of attitudes (Rice \& Aydin, 1991), cognitive maps (Walker, 1985 ), and attributions of leadership (Pastor, Meindl, Mayo, 2002). 
Finally, social networks can also be described at the whole level of analysis. Individual patterns of interaction give configuration to certain structures that can be described from a wholes perspective. Whole-network characteristics are inherent to the social system and are not the property of individual members. Two popular constructs to refer to whole networks are density and centralization. Network Density indicates the degree to which there are numerous and intense links among members of a social network. Network density has been suggested as a sociometric measure of group cohesion (Blau, 1970). Often times, density refers to the proportion of actual to potential contacts in a network (Monge \& Eisenberg, 1987). Other times, as in the case of small groups in which everybody is connected to everybody, researchers centered around the concept of total frequency of interactions divided by the number of links in the team. Network Centralization, on the other hand, describes the configuration of centrality measures among members of the team. Network centralization represents the dispersion of actors' status within the network (Wasserman \& Faust, 1994). High values of group-level centrality indicate that a single individual or a few individuals are quite central, with the remaining group members considerably less central. The concept of group centralization is then a measure of variability and dispersion of individuals' centralities, and, as such, is taken as an indication of status differentials within the work team.

Research studies at the whole network level, however, are very rare. There is a series of small-group lab studies in the 50's (reviewed by Shaw, 1964) showing that centralized networks are more efficient for simple tasks, whereas decentralized networks are more suitable for complex tasks. More recently, Reagans and Zuckerman (2001) found that network density and network heterogeneity are related to productivity in $R \& D$ teams. Yet, given the importance that informal communication networks seems to have for collective action, there seems to be a need for more research studies at this level. In our study, we are focusing on the mediating effects of network density and network centralization on the relationship between diversity and outcomes. We argue that the demographic composition of work teams will determine, to some extent, the communication patterns among team members, which in turn, will influence team effectiveness.

\section{The Effects of Diversity on Intra-group Networks}

There are competing paradigms in diversity research -one explaining the opportunities of diversity and the other its disadvantages. On the opportunity side, the advantages associated with diversity are discussed within a cognitive resource perspective. Diverse teams yield creative and effective solutions because of the variety of cognitive resources available within the team. On the other side, the challenges of diversity are conceptualized using both a sociological and a psychological approach. The sociological approach is based on Pfeffer's (1983) notion of organizational demography that suggests that demographic differences among team members increase communication and coordination problems. The psychological approach, grounded in social identity theory (Tajfel and Turner, 1986), implies that diversity provides a social context in which team members are more likely to make ingroup/outgroup categorizations that create coalitions of demographically similar others. Overall, these three theoretical approaches seem to best represent the cumulative patterns of diversity research and are used here to develop hypotheses liking team diversity, team networks and effectiveness. 
The three theoretical approaches will serve to develop hypotheses linking work team diversity to communication networks. The three perspectives suggest that diverse teams outperform or underperform homogeneous groups because people communicate and interact differently. From a cognitive resource perspective, we could argue that that there is a positive relationship between diversity and the density of communication within the team. The argument is that differences among group members are likely to stimulate discussion and exchange of information because of the need to combine a variety of skills and to accord different points of view. The empirical evidence, however, tends to support this claim only for those types of diversity that are related to the job (see Milliken and Martins, 1996 for a review). The communication benefits of diversity are more likely to manifest themselves for job-related dimensions such as type of education and tenure on the job. Considerable conceptual evidence suggests that the type of formal education and the expertise in some primary functional area greatly influence group members' knowledge base and skills (Hambrick \& Mason, 1984; Holland, 1976). In contrast, the organizational demography perspective would predict that differences among group members make communication with demographically dissimilar others difficult and will result in lower density of the communication network. Differences in terms of sex, race and age do not necessarily lead to differences in knowledge base and skills. Accordingly:

Hypothesis 1a. Social diversity (sex, race, age) will have a negative effect on network density.

Hypothesis 1b. Job-related diversity (education and tenure) will have a positive effect on network density.

Social categories, such as sex, race and age, are generally used by individuals as social and status markers. Social identity theory and status theories (Berger, Cohen, \& Zelditch, 1972) focus on the distribution of the communication rather than the frequency of it. The general notion underlying these theories is that social categories such as sex, age, and race are indicators of status in our society. Based on this notion, Jackson et al. (1995) hypothesized that "because demographics are the cues used in the initial assignments of status, status differentiation occurs whenever demographic diversity is present” (p. 27). Status differentials can be captured by the concept of network centralization. A team network is centralized to the extent that all relations in it involve a single or a few actors (Knoke \& Burt, 1983). Because heterogeneous teams contain more status inequality among their members than homogeneous teams, one can also expect the variance of individual centrality in the communication and resource network to be greater within heterogeneous teams. That is, compared to homogeneous teams, teams composed of dissimilar group members are more likely to have a single or a few members that are highly involved in communication activities compared to the remaining group members. In other words, participation in the exchange of information is likely to be unequal among members of heterogeneous teams, with higher status members participating more. This argument is also consistent with the idea that diversity increases coordination problems in the team (Pfeffer, 1983). A functional response of the team to this coordination challenge may be to centralize their 
network. Thus, diverse teams will centralize their communication to help coordinate their actions.

Hypothesis 2. Social diversity will have a positive effect on network centralization.

\section{Social Networks and Work Team Effectiveness}

The density of the communication network is usually considered an indicator of social cohesion (Blau, 1970; Kincaid, 1988). However, talking may not always be viewed as a good thing. High density of communication among team members that need to make a decision or need to solve a problem may be something positive. However, talking among team members that need to focus on a routine task, talking may be a distraction from the task and be penalized by the team leader. Theoretical support for the relationship between density and team effectiveness can then be found in research on social cohesion. The cohesion-performance relationship is not straightforward. It depends on whether group cohesiveness is based on a shared commitment to the task (task cohesion) or on interpersonal attraction (interpersonal cohesion) (Hackman, 1990). Research evidence suggests that high task cohesion helps performance (Back, 1951; Zaccaro \& Lowe, 1988) because group members are more open to disagree in order to help move the task forward (Hackman, 1990). Cohesion based on interpersonal attraction, however, does not seem to facilitate performance, but it increases team stability. Members of cohesive groups are more committed to the team and less likely to turnover (O'Reilly, et al., 1989). To the extent that task cohesion is reflected in the density of the task communication network, and interpersonal cohesion is reflected by the density of the interpersonal communication network, teams with dense task networks will perform the task better and teams with dense interpersonal networks will achieve better process effectiveness.

Hypothesis 3a. The greater the density of the task network, the higher its task performance.

Hypothesis 3b. The greater the density of the friendship network, the higher its process effectiveness.

Network centralization also has important implications for team effectiveness. Early studies on group centralization suggest that centralized networks are detrimental for the performance of complex tasks (McGrath, 1984). However, on the positive side, the studies reviewed by Shaw (1964) showed that for simple tasks, highly centralized networks were more effective. In the case of diverse teams, centralization may help team members with different backgrounds to coordinate their actions. A centralized group reduces uncertainty and members of diverse teams may find it easier to get along with one another in this type of centralized structures. Centralization may as well help reduce conflicts by assigning central roles to 
individuals who can bridge different cliques in effective ways. In this case, moderate to high levels of centralization may result in higher quality of group processes and higher performance.

Hypothesis 4. Controlling for the routinization of the task, the greater the network centralization of a team, the higher its processes effectiveness and the higher its task performance.

\section{The Effects of Diversity on Work Team Outcomes}

So far, we have discussed a mediated model based on the effects of diversity on the social network of the team. There is also the possibility of diversity having a direct effect on outcomes bypassing the effects on the social networks. The argument is that independent of the team processes, the preconceptions of what good group dynamics and performance is may not match with the dynamics encountered in a diverse team. Diverse teams may have more difficulties with communication and increased conflict, but that might just be part of the way they perform. However, this increased conflict and misunderstanding may trigger in team members and team leaders the stereotype of a dysfunctional team. Accordingly, they may evaluate the team as low performing team regardless of their objective level of performance. These cognitive biases on the part of team members and leaders may result on a direct effect of diversity on team members' ratings of process effectiveness and team leaders' ratings of task performance.

Hypothesis 5: The higher the diversity of the team, the lower the ratings of process effectiveness and task performance. 


\section{METHODOLOGY}

\section{Research Site}

The research was conducted in three different plants of a manufacturing company, called here Graphic Designs. Two of the plants, "Plant 1" (headquarters) and "Plant 2" are located in upstate New York, and the third plant, "Plant 3," is located in California. Two aspects made this company an appropriate sample for this study. First, the firm had very well-defined teams. Most employees were divided into work units or teams to complete tasks. Second, there was a wide range of variability on both the independent and dependent variables. There were homogeneous groups and groups that were very heterogeneous across a range of attributes such as gender, race, age, tenure, and educational background. Also, groups varied in terms of their performance and communication patterns.

\section{Sample}

The sample included 71 work teams from the three different plants of the company. A work team is defined as all personnel who reported directly to the same supervisor, shared a common physical space, and are in a position to engage in regular face-to-face interactions. The 71 work teams consisted of 9 management teams whose primary activity was making decisions concerning a specific organizational department (e.g., the operation management team), 38 professional teams whose primary activity was problem-solving (e.g., quality control teams, customer service teams, finance groups, and management information system teams), and 24 production teams whose primary activity was the actual production of the company products, such as disposable plastic and paper medical devices. The work teams had an average of 7 members, the smallest group had 4 members and the largest group has 15 members. The average tenure of the teams was 6 years, the youngest team had been working for less than 1 year and the oldest team had been operating for 15 years.

These 71 work teams included a total of 439 team members and 44 supervisors. ${ }^{1}$ The response rate for group members was $91 \%$ and the response rate for supervisors was $96 \%$. The demographic description of the sample was as follows: $51 \%$ was male, $84 \%$ white, $10 \%$ black, $4 \%$ Hispanic, and $2 \%$ Asian, their average age was 45.58 years, and their average tenure in the company was 13.37 years.

\section{Procedure}

The procedure involved three steps: identification of work teams, personal distribution of surveys to all employees, and collection of archival data. The first step consisted of the identification of work units. I determined work unit memberships from organizational charts, departmental reports (e.g., staffing report from Human Resources), and organizational layouts.

\footnotetext{
${ }^{1}$ The number of supervisors does not add to 71 because several teams share the same supervisor.
} 
Once I defined the work units, I verified this information in interviews with 2 or 3 supervisors from each department. Second, I met with each superior to set a group appointment in order to distribute the survey. In this group meeting, I explained the nature of the study to the group and I distributed in person a Team Survey to group members and a Supervisory Survey to the superior. They completed the survey in the work setting during normal working hours and returned to me through internal mail or in person. The answers to the surveys were strictly confidential. Questionnaires were coded so that responses from subordinates and supervisors in the same work group could be identified. Finally, demographic data and performance appraisals for each individual participant were recorded from internal archival data. Also, I collected qualitative data through semi-structured interviews with a small sample of participants.

\section{Independent Variables: Team Diversity Measures}

Measures were created to evaluate the diversity of the team based on five demographic attributes -sex, race, age, tenure, and education-. Demographic attributes were coded as follows: Sex - it was measured by a dichotomous variable, with 1 designating male and 2 designating female. Race - it was recorded using the following categories: White, Black, Hispanic, Asian, Native American, and other. Age - date of birth was recorded and then used to compute age. Tenure - it was measured in the number of years since the person first joined the company. Educational type - The type of education for those with some years of college, following Jackson et al. (1991), was measured using a dichotomous variable, indicating whether a person has a concentration in business $(0=$ no, $1=$ yes $)$.

Blau's (1977) index was used to obtain an estimate of the degree of team heterogeneity with respect to the three categorical attributes: sex, race, and educational type. This index measures the degree to which there are a number of categories in a distribution and the dispersion of the group members within these categories. This index of heterogeneity can be expressed as $1-\sum \mathrm{P}_{\mathrm{i}}{ }^{2}$ where $\mathrm{P}$ is the proportion of group members in a category and $\mathrm{i}$ is the number of different categories represented on a team. For example, a team composed of three men and two women is assigned a heterogeneity level in terms of gender of $.38^{2}$. Similarly, applying Blau's index, a team composed of two blacks and three whites will be assigned a value of race heterogeneity of .38 .

The coefficient of variation (the standard deviation divided by the mean) will be used to obtain an estimate of the degree of team heterogeneity with respect to the two continuous variables: age and tenure (measured in years). Allison's (1978) review of measures of inequality in social systems concludes that this index is the most appropriate choice for variables such as age. Also, previous research has found the coefficients of variation with respect to age and tenure in a group to be related to social integration and turnover (e.g., Wagner et al., 1984; O’Reilly et al., 1989).

\footnotetext{
${ }^{2}$ The value of .38 comes from applying the Blau's index as follows: $1-\left[(.75)^{2}+(.25)^{2}\right]$.
} 


\section{Social Network Measures}

To uncover the pattern of social ties, we asked participants to complete a Network Analysis Questionnaire (NAQ). First, to obtain information about the task network, participants are asked, "On average, how many times in a typical week do you find yourself discussing job-related issues with other members of your work unit?” Second, to uncover the friendship-oriented network, respondents are asked, " On average, how many times in a typical week do you socialize or discuss job-unrelated (personal) issues with other members of your work unit?" Participants were given a list with the names of all members of their work group. Two square matrices, $\mathrm{T}(\mathrm{NxN})$ and $\mathrm{F}(\mathrm{NxN})$, are then created for each social network. Based on these matrices, we computed the independent variables.

\section{Network Density}

Density is a measure of frequency of exchange of communication and resources. Density is the proportion of actual to potential contacts in a network (Monge \& Eisenberg, 1987). Mathematically, the density of a network is calculated as the sum of the average level of communication among pairs of team members divided by the size of the team.

\section{Network Centralization}

Refers to the dispersion in a network of individual centrality indices (Hoivik \& Gleditsch, 1975). Thus, a measure of group centralization involves two decisions. First, one needs to decide how individual centrality is measured. The three most common measures of individual centrality are degree, closeness, and betweenness (see Freeman, 1979 for a review). Of the three indices, degree centrality is the simplest definition of activity or involvement in the social system (Wasserman \& Faust, 1994). Central group members are the most active in the sense that they have the most ties to other members in the work team. An individual-level degree centrality index is operationalized as the number of links associated with an individual, and this index is provided as output from the UCINET, a network analysis computer package. Second, once team members' centrality is computed, one needs to decide how the dispersion of these indices is measured. Among all the formulas available to measure dispersion of centrality (see Wasserman \& Faust, 1994 for review), the variance is the most widely recommended (Snijders, 1981; Hoivik \& Gleditsch, 1975; Coleman, 1964). Taken together, a measure of group degree centralization for the communication networks using the variance is used in this study to operationalize team-level centrality. This measure can be represented as follows:

$$
\mathrm{S}_{\mathrm{C}}^{2}=\left[\sum_{i=1}^{g}\left(\mathrm{C}\left(\mathrm{n}_{\mathrm{i}}\right)-\overline{\mathrm{C}}\right)\right] / \mathrm{g}
$$

where $\bar{C}$ is the mean individual degree centrality index. 


\section{Work Team Effectiveness Measures}

\section{Task performance}

The first criterion against which to measure team effectiveness is the actual output of the team. According to Hackman (1987: 323), "the productive output of the work group should meet or exceed the performance standards of the people who receive and/or review the output." Measures of team task performance were obtained by having the immediate supervisor complete the Van de Ven and Ferry's (1980) work group performance scale. Supervisors evaluated their groups in relation to other organizational groups on each of the following seven factors: quantity and quality of performance, number of innovations, reputation for work excellence, goal attainment, efficiency, and moral. All items were evaluated on a five-point scale format, ranging from 1 = far below average to $5=$ far above average. Items were combined into a scale by computing the mean on raw scores.

\section{Process effectiveness}

Because this study centers on group processes, it is also important to evaluate the effectiveness of the interaction process. This information is of theoretical and practical significance. Theoretically, there is reason to believe that group members use outcomes as well as processes as criteria to evaluate their experience in the group. Practically, this information can be useful to identity the strengths and weaknesses of the group and to guide interventions intended to help a group improve its effectiveness (Hackman, 1987). Supervisors evaluated the team according to the following three process criteria suggested by Hackman \& Walton (1986): (1) Effort - the extent to which members build commitment to the group and its task, (2) Skills - the extent to which members share expertise and learn from one another, and (3) Performance Strategies - the extent to which members develop inventive and creative ways of proceeding with the work. These items were also combined into a scale by computing the mean on raw scores.

\section{Control Variables}

The topic of team process and effectiveness has been the subject of a large number of empirical studies that show that many variables might be correlated with group interaction and effectiveness. Several group and organizational variables that may be correlated with the variables of interest need to be controlled for in the study. In this study we included controls for Team size, team familiarity (team average tenure), task routinization and work interdependence. Because the data was obtained from three different plants in the same company, we also included dummy variables for two of the plants. 


\section{Analysis}

Multiple regression analysis was used to estimate the effects of the diversity variables on network and effectiveness measures. We have developed separate regression models for each of the network variables and the effectiveness variables. All the models included teams' size, tenure, task routinization, work interdependence and two dummy variables for company plant as control variables.

The regression weights associated with diversity variables for density and centralization of the communication networks were used to test the first set of hypotheses and hypothesis 2 . Regarding density, positive signs on the regression weights associated with education and tenure diversity and negative signs on the regression weights associated with sex, race, and age diversity would indicate results consistent with the hypotheses. Regarding centralization, positive signs on the regression weights associated with all the diversity variables would indicate results consistent with the hypotheses.

Path analysis was used to examine the extent to which process variables mediate the relationship between diversity and effectiveness. The path analysis was performed for the whole model: diversity-networks-outcomes. This analysis involved two sets of ordinary least squares regressions. In the first set, the network variables were regressed against the diversity variables. The resulting standardized beta value represents the path coefficient from the diversity variable to the communication variable. In the second set of regressions, each effectiveness measure was regressed against the diversity variable (e.g. sex diversity) and the process variable (e.g. density of communication). The standardized beta values represent path coefficients showing the direct path from diversity to effectiveness and from communication to effectiveness. We included the control variables in all the regressions. Even though we did not make explicit hypotheses for the task and friendship communication networks, we run parallel analyses for both networks. In general, we did not obtained significant results for the friendship network. 


\section{RESULTS}

Table 1 shows the intercorrelations among all the variables and Tables 2 and 3 present the regression results. The results show that diversity variables contributed significantly to predict network measures and directly to the effectiveness variables. Four of the five diversity variables have significant regression weights on one or more of the dependent measures. These results support the general notion that the degree of diversity in a team may have significant effects on network patterns such as the density and the centralization of the network and the effectiveness of the team.

\section{[Insert Table 1 about here]}

\section{Diversity and Network Density}

Hypothesis 1a relates social diversity to network density. The results shown in Tables 1 and 2 give support to this hypothesis. Teams diverse with respect to sex, race and age were found to have less dense task networks than relatively more homogeneous teams (beta $=-.25$, $\mathrm{p}<.05$ ), (beta $=-.25, \mathrm{p}<.05$ ), and (beta $=-.21, \mathrm{p}<.1$ ), respectively. Similar results were found for the friendship network (beta $=-.28, \mathrm{p}<.05$ ), (beta $=-.19, \mathrm{p}<.05$ ), and (beta $=-.21, \mathrm{p}<.1$ ) for sex, race and age diversity, respectively. These results hold when the social diversity variables are entered together in the equation, although sex diversity shows the stronger effects $(b=-26$, $\mathrm{p}<.05)$ for task density and $(\mathrm{b}=-30, \mathrm{p}<.05)$ for friendship density.

Hypothesis $1 \mathrm{~b}$ relates job-related diversity to network density. The results partially support this hypotheses. Teams diverse with respect to education and tenure were found to have more dense task networks than relatively more homogeneous teams (beta $=.10$, ns) and (beta $=$ $.35, \mathrm{p}<.10$ ) for tenure and educational diversity respectively. The results for the friendship network were not significant. The results when both job-related diversity variables are entered together in the equation show that education diversity has the stronger effects $(b=.37, p<.05)$ for task density and $(\mathrm{b}=.46, \mathrm{p}<.05)$ for friendship density.

When all diversity measures are entered in the equation, the regression equation shows that job-related diversity has the stronger effects on network density and tend to overcome the effects of social diversity. Tenure diversity shows statistically significant betas for task network density $(b=.46, \mathrm{p}<.05)$ and friendship network density $(\mathrm{b}=.52, \mathrm{p}<.05)$.

\section{[Insert Table 2 and 3 about here]}

\section{Diversity and Network Centralization}

Hypothesis 2 relates social diversity to network centralization. The results shown in Tables 3 and 4 give partial support to this hypothesis. Teams diverse with respect to sex were found to have more centralized task network structures than relatively more homogeneous teams (beta $=.41, \mathrm{p}<.01$ ). Similarly, diverse teams with respect to age were found to have more centralized friendship network structures than relatively more homogeneous teams (beta $=.33$, $\mathrm{p}<.05$ ). These results hold when the social diversity variables are entered together in the 
equation, $(\mathrm{b}=.43, \mathrm{p}<.01)$ for sex diversity and task centralization, and $(\mathrm{b}=.34, \mathrm{p}<.05)$ for age diversity and friendship centralization. When all diversity measures are entered in the equation, the regression equation shows only sex diversity has some effects on task network centralization $(\mathrm{b}=.34, \mathrm{p}<.10)$.

\section{[Insert Table 4 and 5 about here]}

\section{The Mediated Effect of Social Network Variables}

Hypotheses 3 and 4 examine part of the process model concerning with the extent to which the density and the centralization of the network is one of the processes by which diversity influences team effectiveness. Tables 5 and 6 show the results of the regression equations. Hypothesis 3 predicts a positive effect from network density to work team outcomes. The results shown in Tables 3 give partial support to this hypothesis. The density of the network shows positive and statistically marginally significant betas predicting members' evaluations of group processes $(\mathrm{b}=.42, \mathrm{p}<.05)$ and $(\mathrm{b}=.32, \mathrm{p}<.10)$ for the task and friendship network respectively. The results for the supervisors' evaluation of task performance are in the expected direction but they are not statistically significant $(b=.22$, ns) and $(b=21$, ns) for the task and friendship network respectively.

Hypothesis 4 predicts a positive effect from network centralization on work team outcomes after controlling for task routinization. The results support this hypothesis for the task network on members evaluations of group processes $(\mathrm{b}=.41, \mathrm{p}<.10)$ and $(\mathrm{b}=.60, \mathrm{p}<.05)$ when all variables are entered in the equation. The results for the supervisors evaluations of task performance are in the unexpected direction although they are $(b=-.14, n s)$ and $(b=-.08$, ns) for the task and friendship centralization networks respectively.

\section{[Insert Table 6 and 7 about here]}

\section{A Direct Effects Model}

We also hypothesized a direct effects model from work team diversity to work team outcomes. The results show three consistent direct negative effects from team diversity to work team outcomes. First, there is a negative and direct effect of sex and tenure diversity on team members evaluations of group processes $(b=-.44, p<.05)$ and $(b=-.33, p<.10)$. Also, race diversity has a statistically significant negative direct effect on supervisors' evaluations of task performance $(\mathrm{b}=-.62, \mathrm{p}<.01)$. 


\section{Summary of Results}

The results on the diversity variables are generally consistent with the hypotheses. We hypothesized that the effects of social diversity (sex, race and age) and job-related diversity (tenure and education) on work team outcomes were mediated by the pattern of communication that emerges in the team. The two social network concepts examined in this study were significantly affected by the composition in the team. All five diversity measures were connected to the density of the network. Social diversity tends to reduce the density of the network, while job-related diversity tends to increase the density of the network. Similar effects were found for the task network and the friendship network. When all diversity variables are considered together, the strongest effects were found for job-related diversity (tenure and education). The effects on network centralization seem to be more localized. Sex diversity shows a strong positive effect on task network centralization while age diversity seems to centralize the friendship network.

Consistent with previous research on social networks, we found a connection between social network parameters and work team outcomes. Both task network density and task network centralization seem to have positive effects on team members' evaluations of the quality of the group processes. We did not find a strong connection between social network parameters and supervisors' evaluations of team performance, although the effects were in the expected direction. Finally, we also hypothesize direct effects from diversity variables to work team outcomes. Statistically significant negative effects were found for sex and tenure diversity on team processes and for race diversity on supervisors' perceptions of performance. Overall, the results support the basic notion of this study, that team diversity has an effect on team effectiveness mediated by the network communication patterns that develop within the team.

\section{[Insert Figure 1 about here]}

\section{DISCUSSION}

The present research is consistent with recent calls in the organizational behavior literature that advocate the use of network methods and techniques for theory testing (Salancik, 1995; Wasserman and Galaskiewicz, 1994), particularly at the micro-level of analysis (Krackhardt and Brass, 1994). This research also takes demography research a step forward by developing and testing a process model that examines how the demographic diversity of work teams affects network patterns within the team, which in turn influences team effectiveness. Team communication patterns are conceptualized and measured here using network-derived concepts and techniques that allow operationalization of behaviors at the level of teams-aswholes, overcoming some of the limitations of traditional aggregation methods.

In testing this intervening network model, this research also suggests some boundaries to the applicability of three theoretical perspectives to diversity: cognitive resources, organizational 
demography, and social identity. As expected, cognitive resource theory seems to apply to professional diversity (e.g. tenure and education heterogeneity), whereas organizational demography and social identity theory seem to apply to three types of social diversity: sex, race, and age. Furthermore, the cognitive resource perspective makes predictions regarding the density of the network, whereas the other two approaches make predictions regarding the centralization of the network.

Consistent with cognitive resource theory, mixed-education teams reported relatively more dense communication networks and were rated as having better team processes. Differences in education appear to reflect underlying differences in experiences and knowledge base that may stimulate discussion because they have different cognitive bases. In contrast, consistent with the organizational demography and social identity, results for sex diversity show that mixed-sex teams report higher centralized communication networks than relatively more homogeneous teams. In turn, teams with higher centralization received the most favorable group maintenance ratings. Thus, the overall indirect effect of these types of diversity on effectiveness is positive rather than negative. Thus, this favorable process effectiveness rating may reflect team members' preference for a rather hierarchical work team.

The study also makes an important contribution the social networks literature by focusing on the antecedents and consequences of whole network concepts. While most of the research on the intra-organizational networks has centered around individuals position in the network (see Krakhardt \& Brass, 1994), there is a lack of studies examining the emergent network properties of the team as a whole. In our study, we suggest that the composition of the team is one the critical factors behind the configuration of the team network structure.

Taken as a whole, this study illustrates the potential value of examining intragroup networks as intervening variables when attempting to understand the effects of diversity on team outcomes. The increasing diversity in the workplace (Jackson \& Alvarez, 1992) and the popularity of team work (Walton \& Hackman, 1986) are bringing more people to work with others who differ in their backgrounds, values, and assumptions. As this increased diversity represents both opportunities and challenges, managers are looking for ways to maximize its benefits while minimizing its disadvantages. The results of this study may help managers to deal with diversity issues by laying out some of the network mechanisms through which diversity influences team effectiveness and offer some clues about what might maximize the advantages of diversity and minimize its challenges. 


\section{REFERENCES}

Allison, C. P. 1978. Measures of inequality. American Sociological Review, 43:865-880.

Back, K. 1951. Influence through social communication. Journal of Abnormal Social Psychology, 46, 9-23.

Blau, P.M. 1970. A Formal Theory of Differentiation in Organizations. American Sociological Review, 35, 201-218

Blau, P.M. 1977. Inequality and Heterogeneity. New York: The Free Press.

Berger, J. B., Cohen, B. P., \& Zelditch, M. Jr. 1972. Status characteristics and social interaction. American Sociological Review, 37, 241-255.

Borgatti, S.P., Everett, M.G., \& Freeman, L.C. 1992. UCINET IV Version 1.0. Columbia: Analytic Technologies.

Brass, D.J. 1984. Being in the right place: A structural analysis of individual influence in an organization. Administrative Science Quarterly, 29: 518-539.

Burkhardt, M.E. \& Brass, D. 1990. Changing patterns or patterns of change: The effects of change in technology on network structure and power. Administrative Science Quarterly, 35: 104-127.

Chatman, J.A., Polzer, J.T., Barsade, S.G., \& Neale, M.A. 1998. Being different yet feeling similar: The influence of demographic composition and organizational culture on work processes and outcomes. Administrative Science Quarterly, 43, 749 - 780.

Coleman, J. 1964. Introduction to Mathematical Sociology. New York: Free Press

Danowski, J. 1980. Group attitude conformity and connectivity of organizational communication networks for production, innovation and maintenance content. Human Communication Research, 6, 299-308.

Farace, R.V., P.R. Monge \& H. M. Russell. 1977. Communicating and organizing. Menlo Park, CA, Addison-Wesley.

Freeman, L.C.1979. Centrality in social networks: Conceptual clarification. Social Networks, 1: 215-239.

Hackman, R. J. 1990. Groups that Work (and those that don't). CA: Jossey-Bass.

Hackman, R. J. 1987. The design of work teams. In J. W. Lorsch (Ed.), Handbook of Organizational Behavior: 315-342. Englewood Cliffs, NJ: Prentice-Hall. 
Hambrick, D. C., \& Mason, P. A. 1984. Upper echelons: The organization as a reflection of its top managers. Academy of Management Review, 9: 193-206.

Harrison, , D. A., Price, K. H., \& Bell, M. P. 1998. Beyond rational demography: Time and the effects of surface and deep-level diversity on work group cohesion. Academy of Management Journal, 41, 96-107

Holland, J. L. 1976. Vocational preferences. In Dunnette, M. D. (Ed.). Handbook of Industrial / Organizational Psychology. Rand McNally, Chicago, Il.

Hoivik, T. \& N. Gleditsch. 1975. Structural parameters of graphs: A theoretical investigation. In Blalock et al. (Eds.). Quantitative sociology. New York, Academic Press.

Ibarra, H., \& Andrews, S. B. 1993. Power, social influence, and sense making: Effects of network centrality and proximity on employee perceptions. Administrative Science Quarterly, 38, 277-303.

Jackson, S. E., \& Alvarez, E. B. 1992. Working through diversity as a strategic imperative. In S. E. Jackson (Ed.). Diversity in the WorkPlace (pp. 13-35). New York: Guilford Press.

Jackson, S. E., Brett, J. R., Sessa, V. I., Cooper, D., M., Julin, J. A., \& Peyronnin, K. 1991. Some differences make a difference: Individual dissimilarity and group heterogeneity as correlates of recruitment, promotions, and turnover. Journal of Applied Psychology, 76: 675-689.

Jackson, S. E., May, K. E., \& Whitney, K. 1995. Understanding the dynamics of diversity in decision making teams. In R. A. Guzzo \& E. Salas (Eds.). Team Effectiveness and Decision Making in Organizations: 204-261. San Francisco: Jossey-Bass.

Kinkaid , L. (1988). The convergence theory of communication: Its implication for intercultural communication. IN Y.Y. Kim (Ed.), International and Intercultural Annual, Vol 12, Theoretical Perspectives on International Communication, pp. 280-298. Beverly Hills: Sage.

Knoke, D., \& Burt, R.S. 1983. Prominence. In R.S. Burt \& M.J. Miner (Eds.), Applied network analysis: A methodological introduction (pp. 195-222). Beverly Hills, CA: Sage

Krackhardt, D., \& Brass, D.J.1994. Intraorganizational networks: The micro side. In S. Wasserman \& J. Galaskiewicz (Eds.). Advances in social network analysis, 207-229.

Krackhardt, D., \& Porter, L.W. 1986. The snowball effect: Turnover embedded in communication networks. Journal of Applied Psychology, 71, 50-55.

Lawrence, B.S. 1997. The black box of organizational demography. Organizational Science, 8, 1-22.

Leavitt, H.J. 1951. Some effects of certain communication patterns on group performance. Journal of Abnormal and Social Psychology, 46: 38-50. 
Mayo, M. 1999. Capitalizing on a Diverse Workforce. Ivey Business Journal, September/October, 20-26.

McGrath, J. E. 1984. Groups: Interaction and performance. Englewood Cliffs, NJ: Prentice-Hall.

Milliken, F. J., \& Martins, L. L. 1996. Searching for common threats: Understanding the multiple effects of diversity in organizational groups. The Academy of Management Review, 21: 402-433.

Monge, P. R. and Eisenberg, E. 1987. Emergent networks. In Jablin, Putman, Roberts, and Porter (Eds.), Handbook of Organizational Behavior (pp. 304-342). Beverly Hills, CA: Sage.

O’Reilly, C. A., Caldwell, D. F., \& Barnett, W. P. 1989. Work group demography, social integration and turnover. Administrative Science Quarterly, 34: 21-37.

Pastor, J-C, Meindl, J.R. \& Mayo, M.C. 2002. A networks effects model of charisma attributions. Academy of Management Journal, 45: 410-420.

Pfeffer, J. 1983. Organizational demography. In L. L. Cummings \& B. M. Staw (Eds.), Research in Organizational Behavior, 5: 299-357. Greenwich, CT: JAI Press.

Pfeffer, J., \& O’Reilly, C. A. 1987. Hospital demography and turnover among nurses. Industrial Relations, 26: 158-173.

Polzer, J.T., Milton, L.P., \& Swann, W. Jr. 2002. Capitalizing on diversity: Interpersonal congruence in small work groups. Administrative Science Quarterly, 47(2): 296-324.

Reagans, R., \& Zuckerman, E. 2001. Networks, diversity, and productivity: The social capital of corporate R\&D teams. Organization Science, 12(4), 502-517.

Rice, R. E., \& Aydin, C. 1991. Attitudes toward new organizational technology: Network proximity as a mechanism for social information processing. Administrative Science Quarterly, 36(2), 219-245.

Roberts, K.H., \& O’Reilly, C.A. III. 1979. Some correlates of communication roles in organizations. Academy of Management Journal, 22: 42-57.

Salancik, G. 1995. Wanted: A good network theory of organization. Administrative Science Quarterly, 40: 345-349.

Snijders, T. A. B. 1981. The degree variance: An index of graph heterogeneity. Social Networks, 3: $164-174$

Shaw, M. 1964. Communication networks. In L. Berkowitz (Ed.), Advances in experimental social psychology (pp. 111-147). New York: Academic Press. 
Tajfel, H., \& Turner, J. C. 1986. The social identity theory of intergroup behavior. In S. Worchel \& W. G. Austin (Eds.), Psychology of Intergroup Relations. Chicago: Nelson-Hall.

Van de Ven, A.H. y Ferry, D.L. 1980. Measuring and Assessing Organizations. New York: Wiley

Walker, G. 1985. Network position and cognition in a computer firm. Administrative Science Quarterly, 30: 103-130.

Wagner, G. W., Pfeffer, J., \& O’Reilly, C. A. 1984. Organizational demography and turnover in top-management groups. Administrative Science Quarterly, 29: 74-92.

Walton, R. W., \& Hackman, J. R. 1986. Groups under contrasting management strategies. In P. S. Goodman (Ed.). Designing Effective Work Groups. San Francisco: Jossey-Bass.

Watson, W.E., Kumar, K., \& Michaelsen, L.K. (1993). Cultural Diversity's Impact on Interaction Process and Performance: Comparing Homogeneous and Diverse Task Groups. Academy of Management Journal. 36, 590-602.

Wasserman, S., \& Faust, K. 1994. Social network analysis: Methods and applications. New York, Cambridge University Press.

Wasserman, S., \& Galaskiewicz, J., (Eds.) 1994. Advances in social network analysis: Research, from the social and behavioral sciences. Newbury Park, CA: Sage.

Weiserman, M. F., \& Bantel, K. A. 1992. Top management team demography and corporate strategic change. Academy of Management Journal, 35: 91-121.

Williams, K. Y., \& O’Reilly, C. A. 1998. Demography and diversity in organizations: A review of 40 years of research. In B. Staw \& R. Sutton (Eds.), Research in Organizational Behavior (Vol. 20, pp. 77-140). Greenwich, CT: JAI Press.

Zaccaro, S.J. \& Lowe, C.A. (1988). Cohesiveness and performance on an additive task: Evidence for multidimensionality. The journal of Social Psychology, 128: 547-558.

Zenger, T. R., \& Lawrence, B. S. 1989. Organizational demography: The differential effects of age and tenure distributions on technical communication. Academy of Management Journal, 32: 353-376. 
Table 1. Correlation matrix among all variables

\begin{tabular}{|c|c|c|c|c|c|c|c|c|c|c|c|c|c|c|c|c|c|c|}
\hline & 1 & 2 & 3 & 4 & 5 & 6 & 7 & 8 & 9 & 10 & 11 & 12 & 13 & 14 & 15 & 16 & 17 & 18 \\
\hline \multicolumn{19}{|l|}{\begin{tabular}{|l} 
Effectiveness Variables \\
\end{tabular}} \\
\hline \multicolumn{19}{|l|}{ 1. Task perfomance } \\
\hline 2. Group Maintenance &, $76^{* * *}$ & & & & & & & & & & & & & & & & & \\
\hline 3. Intention to Stay &,- 00 &,- 07 & & & & & & & & & & & & & & & & \\
\hline \multicolumn{19}{|l|}{\begin{tabular}{|c|} 
Network Variables \\
\end{tabular}} \\
\hline 4. Density friendship &,- 23 &,$- 51^{* * *}$ &,- 18 & & & & & & & & & & & & & & & \\
\hline 5. Density task &,- 21 &,$- 51^{* * *}$ &,- 05 & $90^{* *}$ & & & & & & & & & & & & & & \\
\hline 6. Centralization friendship &,- 05 & 08 &, 16 &,$- 33^{* * *}$ &,$- 33^{* * *}$ & & & & & & & & & & & & & \\
\hline 7. Centralization task &, 17 & $30^{*}$ &, 16 &,$- 38^{* * *}$ &,$- 39^{* * *}$ & $47^{* *}$ & & & & & & & & & & & & \\
\hline \multicolumn{19}{|l|}{\begin{tabular}{|c|} 
Diversity variables \\
\end{tabular}} \\
\hline 8. Sex &, $26^{*}$ & $42^{* * *}$ &,- 20 &,$- 34^{* *}$ &,$- 39^{* * *}$ & 15 &, $33^{* * *}$ & & & & & & & & & & & \\
\hline 9. Race &,- 13 & .18 &, 05 &,- 21 &,$- 27^{*}$ &, 22 & $28^{*}$ &,- 01 & & & & & & & & & & \\
\hline 10. Age &,- 10 &,- 04 &, 03 &,$- 27^{*}$ &,$- 25^{*}$ & $32^{* *}$ & 12 &,- 15 &, $38^{* * *}$ & & & & & & & & & \\
\hline 11. Tenure &, $27^{*}$ &, $43^{* * *}$ &,- 09 &,$- 43^{* *}$ &,$- 41^{* * *}$ &, 14 &, 05 &, 18 & 04 &, $26^{*}$ & & & & & & & & \\
\hline 12. Education & ,19 & 22 &,- 38 &,- 11 &, 03 &, 04 &,- 03 & $36^{*}$ & 01 &,- 23 & 12 & & & & & & & \\
\hline \multicolumn{19}{|l|}{\begin{tabular}{|c} 
Control Variables \\
\end{tabular}} \\
\hline 13. Group Size & ,15 & 19 &,- 05 &,$- 28^{*}$ &,$- 34^{* * *}$ & $26^{*}$ & $30^{*}$ & $26^{*}$ & 18 &, 14 & 09 &,- 12 & & & & & & \\
\hline 14. Group tenure &,- 02 & 10 &, 02 &,- 24 &,- 24 & .11 & $28^{*}$ & 01 & .00 &, $24^{*}$ & 22 &,$- 34^{*}$ &, $28^{*}$ & & & & & \\
\hline 15. Task type &,$- 47^{* *}$ &,$- 65^{* *}$ &,- 15 & $61^{* *}$ &, $66^{* * *}$ & 05 &,$- 32^{*}$ &,$- 38^{* *}$ &,- 13 &,- 09 &,$- 41^{* *}$ &, $36^{*}$ &,$- 37^{*}$ &, $38^{* * *}$ & & & & \\
\hline 16. Work Interdependence &, $27^{*}$ & $40^{* * *}$ &, 09 &,- 13 &,- 10 &, 10 &, 20 &, 20 & 16 &, 06 & 19 & 02 &,- 03 & 02 &,- 15 & & & \\
\hline 17. Plant: CA &,$- 31^{*}$ &,$- 53^{* * *}$ &, 10 &, $75^{* *}$ &, $75^{* * *}$ &,- 14 &,- 12 &,- 28 &,- 12 &,$- 31^{* * *}$ &,- 69 &, 06 &,$- 26^{*}$ &, $36^{* * *}$ &, $72^{* *}$ &,- 07 & & \\
\hline 18. Plant: PA &,- 02 &, 12 &, 10 &,- 21 &,- 23 &, 14 & $27^{*}$ &,- 17 & $48^{* * *}$ &, $51^{* * *}$ & 21 &,- 20 &, 13 &, 06 &,- 14 &, $30^{*}$ &,$- 33^{* * *}$ & \\
\hline
\end{tabular}

Note: $\mathrm{N}=71 ; * \mathrm{p}<.05 ; * * \mathrm{p}<.01$ 
Table 1. Resul ts from the Hierarchical Regression Analysis (standardized betas are reported) on the Density of the Task Network

\begin{tabular}{|c|c|c|c|c|c|c|c|c|}
\hline \multicolumn{9}{|c|}{ DV: TASK NETWORK DENSITY } \\
\hline & I & II & III & IV & $\mathbf{V}$ & \begin{tabular}{|c|} 
Social \\
Diversity
\end{tabular} & \begin{tabular}{|c|} 
Job \\
Diversity
\end{tabular} & ALL \\
\hline \multicolumn{9}{|l|}{ Control Variables } \\
\hline Team size & -.06 & -.13 & -.13 & -.14 & $-.52 * *$ & -.02 & $-.50 * *$ & $-.55 * *$ \\
\hline Tenure & .00 & .03 & .07 & .04 & $.48 *$ & .01 & $.46 *$ & $.49 *$ \\
\hline Task rutinization & $.27+$ & .23 & $.37 *$ & .28 & -.04 & .27 & -.13 & -.13 \\
\hline $\begin{array}{l}\text { Work } \\
\text { interdependence }\end{array}$ & .05 & .00 & -.04 & -.04 & .00 & .05 & -.05 & -.05 \\
\hline Plant: CA & -.15 & .08 & .02 & -.05 & .24 & .02 & .30 & .29 \\
\hline Plant: PA & $.39 * *$ & $.53 * *$ & $.37 *$ & $.52 *$ & .12 & $.41 *$ & .34+ & .25 \\
\hline$R^{2}$ & .56 & .56 & .56 & .56 & .25 & .56 & .25 & .25 \\
\hline $\boldsymbol{F}$ & $9.61 * *$ & $9.61 * *$ & $9.61 * *$ & $9.61 * *$ & 1.58 & $9.31 * *$ & 1.58 & 1.55 \\
\hline \multicolumn{9}{|l|}{\begin{tabular}{|l|} 
Diversity \\
Variables
\end{tabular}} \\
\hline Sex diversity & $-.25 *$ & - & - & - & - & $-26 * *$ & - & .00 \\
\hline Race diversity & - & $-.25 *$ & - & - & - & $-20+$ & - & .19 \\
\hline Age diversity & - & - & $-.21+$ & - & - & $-19+$ & - & .03 \\
\hline Tenure diversity & - & - & - & .10 & - & - & $.32+$ & $.43 *$ \\
\hline Education diversity & - & - & - & - & $.35+$ & - & $37 *$ & $.32+$ \\
\hline Change in $R^{2}$ & .04 & .03 & .03 & .01 & .06 & .11 & .16 & .19 \\
\hline F change & 4.92* & $4.77+$ & $3.47+$ & .41 & 2.57 & $4.62 * *$ & $3.58 *$ & 1.52 \\
\hline$R^{2}$ & .61 & .60 & .59 & .57 & .31 & .67 & .40 & .44 \\
\hline F total & $9.66 * *$ & $9.35 * *$ & $9.18 * *$ & $8.02 * *$ & 1.79 & $9.28 * *$ & $2.29+$ & 1.61 \\
\hline
\end{tabular}

Note: $\mathrm{N}=71 ; \dagger \mathrm{p}<.1 ; * \mathrm{p}<.05 ; * * \mathrm{p}<.01$ 
Table 3. Resul ts from the Hierarchical Regression Analysis (standardized betas are reported) on the Density of the Friendship Network

\begin{tabular}{|c|c|c|c|c|c|c|c|c|}
\hline \multicolumn{9}{|c|}{ DV: FRIENDSHIP NETWORK DENSITY } \\
\hline & $\mathbf{I}$ & II & III & IV & $\mathbf{V}$ & \begin{tabular}{|c|} 
Social \\
Diversity
\end{tabular} & \begin{tabular}{|c|} 
Job \\
Diversity \\
\end{tabular} & ALL \\
\hline \multicolumn{9}{|l|}{ Control Variables } \\
\hline Team size & .02 & -.06 & -.07 & -.07 & $-.31+$ & .06 & -.28 & -.33 \\
\hline Tenure & -.05 & -.01 & .03 & -.01 & $.35+$ & -.05 & .28 & .31 \\
\hline Task rutinization & $.31 *$ & $.29+$ & $.41 *$ & $.33 *$ & .13 & $.34 *$ & .06 & .05 \\
\hline $\begin{array}{l}\text { Work } \\
\text { interdependence }\end{array}$ & .05 & -.05 & -.08 & -.08 & -.15 & .02 & -.21 & -.16 \\
\hline Plant: CA & -.14 & .07 & .05 & -.03 & .19 & .00 & .23 & .25 \\
\hline Plant: PA & $.36 *$ & $.48 *$ & $.35 *$ & $.46 *$ & .29 & $.35 *$ & $.56 * *$ & $.59 * *$ \\
\hline$R^{2}$ & .54 & .54 & .54 & .54 & .23 & .54 & .23 & 0,24 \\
\hline $\boldsymbol{F}$ & $8.82 * *$ & $8.59 * *$ & $8.82 * *$ & $8.82 * *$ & 1.40 & $8.59 * *$ & 1.40 & 1,50 \\
\hline \multicolumn{9}{|l|}{ Diversity Variables } \\
\hline Sex diversity & $-28 *$ & - & - & - & - & $-30 * *$ & - & $-0,04$ \\
\hline Race diversity & - & $-19 *$ & - & - & - & -14 & - & 0,06 \\
\hline Age diversity & - & - & $-21+$ & - & - & $-21+$ & - & 0,01 \\
\hline Tenure diversity & - & - & - & .07 & - & - & -14 & $0,52^{*}$ \\
\hline Education diversity & - & - & - & - & -.10 & - & $46^{* * *}$ & $-0,16$ \\
\hline Change in $R^{2}$ & .06 & .03 & .03 & .00 & .01 & .11 & .15 & 0,19 \\
\hline F change & $6.23 * *$ & 2.48 & $3.19+$ & .21 & .21 & $4.39 * *$ & $3.23+$ & 1,51 \\
\hline$R^{2}$ & .60 & .57 & .58 & .54 & .23 & .66 & .38 & 0,43 \\
\hline F total & $9.35 * *$ & $7.97 * *$ & $8.40 * *$ & $7.46 * *$ & 1.20 & $8.54 * *$ & $2.02+$ & 1.58 \\
\hline
\end{tabular}

Note: $\mathrm{N}=71 ; \dagger \mathrm{p}<.1 ; * \mathrm{p}<.05 ; * * \mathrm{p}<.01$ 
Table 4. Resul ts from the Hierarchical Regression Analysis (standardized betas are reported) on the Centralization of the Task Network

\begin{tabular}{|c|c|c|c|c|c|c|c|c|}
\hline \multicolumn{9}{|c|}{ DV: TASK NETWORK CENTRALIZATION } \\
\hline & I & II & III & IV & $\mathbf{V}$ & $\begin{array}{c}\text { Social } \\
\text { Diversity }\end{array}$ & $\begin{array}{c}\text { Job } \\
\text { Diversity }\end{array}$ & ALL \\
\hline \multicolumn{9}{|l|}{ Control Variables } \\
\hline Team size & .10 & .19 & .24 & .24 & .18 & .03 & .18 & .08 \\
\hline Tenure & $.34 *$ & $.29 *$ & $.26+$ & $.27+$ & $.35+$ & $.38 * *$ & $.34+$ & $.47^{*}$ \\
\hline Task rutinization & -.29 & -.30 & -.35 & $-.38+$ & .05 & -.28 & .04 & -.14 \\
\hline $\begin{array}{l}\text { Work } \\
\text { interdependence }\end{array}$ & -.05 & .08 & .08 & .06 & -.02 & -.04 & -.03 & -.06 \\
\hline Plant: CA & $.34+$ & .24 & .29 & .25 & $.54 * *$ & .33 & $.58 * *$ & $.77^{* *}$ \\
\hline Plant: PA & .39 & .16 & .23 & .39 & .25 & $.33+$ & .26 & $.39^{*}$ \\
\hline$R^{2}$ & .31 & .31 & .31 & .31 & .45 & .31 & .45 & .46 \\
\hline$F$ & $3.23 * *$ & $3.23 * *$ & $3.23 * *$ & $3.23 * *$ & $4.00 * *$ & $3.23 * *$ & $4.00 * *$ & $3.97^{* *}$ \\
\hline \multicolumn{9}{|l|}{\begin{tabular}{|l} 
Diversity \\
Variables
\end{tabular}} \\
\hline Sex diversity & $.41 * *$ & - & - & - & - & $.43 * *$ & - & $.34 \dagger$ \\
\hline Race diversity & - & -17 & - & - & - & .15 & - & -.21 \\
\hline Age diversity & - & - & -02 & - & - & .04 & - & -.13 \\
\hline Tenure diversity & - & - & - & .11 & - & - & .07 & .13 \\
\hline Education diversity & - & - & - & - & .11 & - & .10 & .02 \\
\hline Change in $R^{2}$ & .12 & .02 & .00 & .01 & .01 & .15 & .01 & .09 \\
\hline F change & $8.97 * *$ & 1.31 & .01 & .35 & .31 & $3.79 *$ & .25 & .92 \\
\hline$R^{2}$ & .43 & .33 & .31 & .31 & .46 & .46 & .46 & .55 \\
\hline F total & $4.55 * *$ & $2.98 *$ & $2.71 *$ & $2.78 *$ & $3.39 * *$ & $3.84 * *$ & $2.91 *$ & $2.55^{*}$ \\
\hline
\end{tabular}

\footnotetext{
Note: $\mathrm{N}=71 ; \dagger \mathrm{p}<.1 ;{ }^{*} \mathrm{p}<.05 ;{ }^{* *} \mathrm{p}<.01$
} 
Table 5. Resul ts from the Hierarchical Regression Analysis (standardized betas are reported) on the Centralization of the Friendship Network

\begin{tabular}{|c|c|c|c|c|c|c|c|c|}
\hline \multicolumn{9}{|c|}{ DV: FRIENDSHIP NETWORK CENTRALIZATION } \\
\hline & I & II & III & IV & $\mathbf{V}$ & \begin{tabular}{|c|} 
Social \\
Diversity
\end{tabular} & \begin{tabular}{|c|} 
Job \\
Diversity
\end{tabular} & ALL \\
\hline \multicolumn{9}{|l|}{ Control Variables } \\
\hline Team size & .17 & .17 & .22 & .23 & .20 & .07 & .21 & .07 \\
\hline Tenure & .19 & .20 & .11 & .16 & .31 & .21 & .30 & $.41+$ \\
\hline Task rutinization & $.42+$ & $.45+$ & .30 & .36 & .13 & .35 & .14 & -.02 \\
\hline $\begin{array}{l}\text { Work } \\
\text { interdependence }\end{array}$ & -.04 & .03 & .04 & .01 & -.01 & -.02 & -.02 & -.02 \\
\hline Plant: CA & -.20 & -.29 & -.15 & -.14 & .17 & -.13 & .21 & .42 \\
\hline Plant: PA & .10 & -.08 & -.11 & .04 & -.13 & -.06 & -.12 & -.01 \\
\hline$R^{2}$ & .14 & .13 & .14 & .14 & .24 & .13 & .24 & .25 \\
\hline $\boldsymbol{F}$ & 1.14 & 1.09 & 1.14 & 1.15 & 1.55 & 1.08 & 1.56 & 1.53 \\
\hline \multicolumn{9}{|l|}{ Diversity Variables } \\
\hline Sex diversity & .20 & - & - & - & - & 25 & - & .29 \\
\hline Race diversity & - & .22 & - & - & - & 15 & - & -.19 \\
\hline Age diversity & - & - & $.33 *$ & - & - & $34 *$ & - & .02 \\
\hline Tenure diversity & - & - & - & .09 & - & - & .06 & .14 \\
\hline Education diversity & - & - & - & - & .07 & - & .07 & -.01 \\
\hline Change in $R^{2}$ & .03 & .04 & .08 & .00 & .00 & .15 & .01 & .07 \\
\hline F change & 1.45 & 1.83 & $4.35 *$ & .21 & .10 & $2.80+$ & .10 & .48 \\
\hline$R^{2}$ & .16 & .17 & .22 & .14 & .24 & .28 & .25 & .32 \\
\hline F total & 1.20 & 1.87 & 1.68 & .97 & 1.31 & 1.75 & 1.12 & .98 \\
\hline
\end{tabular}

Note: $\mathrm{N}=71 ; \dagger \mathrm{p}<.1 ; * \mathrm{p}<.05 ; * * p<.01$ 
Table 6. Resul ts from the Hierarchical Regression Analysis (standardized betas are reported) on Members' Perceptions of the Quality of the Group Processes

\begin{tabular}{|c|c|c|c|c|c|c|c|}
\hline \multicolumn{8}{|c|}{ DV: MEMBERS' PERCEPTIONS OF THE QUALITY OF THE GROUP PROCESSES } \\
\hline & I & II & III & IV & \begin{tabular}{|c|} 
TASK \\
NETWORK
\end{tabular} & \begin{tabular}{|c|} 
FRIEND. \\
NETWORK
\end{tabular} & $\begin{array}{c}\text { All } \\
\text { Networks }\end{array}$ \\
\hline \multicolumn{8}{|l|}{ Control Variables } \\
\hline Team size & .20 & .07 & -.07 & -.05 & .18 & .05 & .20 \\
\hline Tenure & -.36 & -.25 & -.36 & -.23 & $-.61 * *$ & -.28 & $-.62 *$ \\
\hline Task rutinization & .01 & -.06 & .02 & -.04 & .09 & -.06 & .07 \\
\hline $\begin{array}{l}\text { Work } \\
\text { interdependence }\end{array}$ & $.31+$ & \multicolumn{2}{|c|}{$.34+.31+$} & .29 & $.34 *$ & $.33+$ & $.38 *$ \\
\hline Plant: CA & $-.41+$ & $-.37+$ & $-.46 *$ & .26 & $-.62 * *$ & -.36 & $-.68 * *$ \\
\hline Plant: PA & .23 & .15 & .00 & -.32 & -.16 & .13 & -.30 \\
\hline $\mathbf{R}^{2}$ & .35 & .35 & .35 & .35 & .35 & .35 & .35 \\
\hline $\mathbf{F}$ & $2.56 * *$ & $2.56 * *$ & $2.56 * *$ & $2.56 * *$ & $2.56 * *$ & $2.56 * *$ & $2.56 * *$ \\
\hline \multicolumn{8}{|l|}{ Diversity Variables } \\
\hline Sex diversity & -.26 & -.25 & $-.41+$ & -.32 & $-.43 *$ & -.29 & $-0.42 *$ \\
\hline Race diversity & .04 & .10 & .21 & .15 & .13 & .12 & 0.14 \\
\hline Age diversity & .00 & .01 & .07 & .01 & .06 & .01 & -0.08 \\
\hline Tenure diversity & -.24 & -.23 & -.12 & -.09 & $-.34+$ & -.22 & $-0.40+$ \\
\hline Education diversity & -.07 & .12 & .06 & .07 & -.09 & .11 & -0.02 \\
\hline \multicolumn{8}{|l|}{\begin{tabular}{|l|} 
Network Variables \\
\end{tabular}} \\
\hline Task Density & $.42 *$ & - & - & - & $.47 *$ & - & .35 \\
\hline Friendship Density & - & $.31+$ & - & - & - & .28 & .24 \\
\hline Task Centralization & - & - & $.44+$ & - & $.50 *$ & - & $.61 *$ \\
\hline Friendship Centraliz. & - & - & - & .18 & - & .11 & -.15 \\
\hline Change in $R^{2}$ & .10 & .06 & .09 & .02 & .21 & .06 & 0.23 \\
\hline F change & $4.36^{*}$ & 2.26 & $3.71+$ & .87 & $5.67 *$ & 1.23 & $2.88 *$ \\
\hline$R^{2}$ & .50 & .46 & .49 & .42 & .61 & .46 & 0.63 \\
\hline F total & 1.82 & 1.53 & 1.73 & 1.34 & $2.50 *$ & 1.39 & $2.12+$ \\
\hline
\end{tabular}

Note: $\mathrm{N}=71 ; \dagger p<.1 ; * p<.05 ; * * p<.01$ 
Table 7. Resul ts from the Hierarchical Regression Analysis (standardized betas are reported) on Supervisors' Perceptions of the Performance of the Team

\begin{tabular}{|c|c|c|c|c|c|c|c|}
\hline \multicolumn{8}{|c|}{ DV: SUPERVISORS' PERCEPTIONS OF THE PERFORMANCE OF THE TEAM } \\
\hline & & & & & TASK & FRIEND & $\mathbf{A L L}$ \\
\hline \multicolumn{8}{|l|}{ Control Variables } \\
\hline Team size & .09 & .05 & .00 & -.02 & .10 & .07 & .11 \\
\hline Tenure & -.08 & -.03 & .14 & .06 & .02 & .01 & .02 \\
\hline Task rutinization & $-.75 * *$ & $-.79 * *$ & $-.81 * *$ & $-.78 * *$ & $-.78 * *$ & $-.79 * *$ & -.78 \\
\hline Work interdependence & .34 & $.36 *$ & $.31+$ & $.33 *$ & $.33 *$ & $.37 *$ & $.34+$ \\
\hline Plant: CA & .11 & .12 & .25 & .17 & .18 & .11 & .15 \\
\hline Plant: PA & $.69 * *$ & $.62 *$ & $.92 * *$ & $.77 * *$ & $.85 * *$ & .65 & $.81 *$ \\
\hline$R^{2}$ & .32 & .32 & .32 & .32 & .32 & .32 & .32 \\
\hline $\boldsymbol{F}$ & $2.09+$ & $2.09+$ & $2.09+$ & 2.09+ & $2.09+$ & $2.09+$ & $2.09+$ \\
\hline \multicolumn{8}{|l|}{ Diversity Variables } \\
\hline Sex diversity & .09 & .10 & .16 & .10 & .16 & .13 & .16 \\
\hline Race diversity & $-.60 * *$ & $-.56 * *$ & $-.60 * *$ & $-.57 * *$ & $-.63 * *$ & $-.59 * *$ & $-.64 * *$ \\
\hline Age diversity & -.08 & -.08 & -.10 & -.09 & -.10 & -.08 & -.10 \\
\hline Tenure diversity & .22 & .20 & $.34 *$ & $.32+$ & .25 & .20 & .22 \\
\hline Education diversity & .18 & .28 & .25 & .25 & .18 & .29 & .20 \\
\hline \multicolumn{8}{|l|}{\begin{tabular}{|l|} 
Network Variables \\
\end{tabular}} \\
\hline Task Density & .22 & - & - & - & .21 & - & .18 \\
\hline Friendship Density & - & .21 & - & - & - & .25 & .07 \\
\hline Task Centralization & - & - & -22 & - & -.19 & - & -.14 \\
\hline Friendship Centraliz. & - & - & - & -.05 & - & -.12 & -.08 \\
\hline Change in $R^{2}$ & .03 & .03 & .02 & .00 & .05 & .04 & .05 \\
\hline F change & 1.66 & 1.45 & 1.22 & .11 & 1.31 & .96 & .64 \\
\hline$R^{2}$ & .64 & .63 & .63 & .61 & .65 & .64 & .66 \\
\hline F total & $3.04 *$ & $3.00 *$ & $2.95 *$ & $2.71 *$ & $2.88 *$ & $2.74 * *$ & $2.28+$ \\
\hline
\end{tabular}


Figure 1. Path Diagram of Diversity- Networks -Effectiveness Relationship

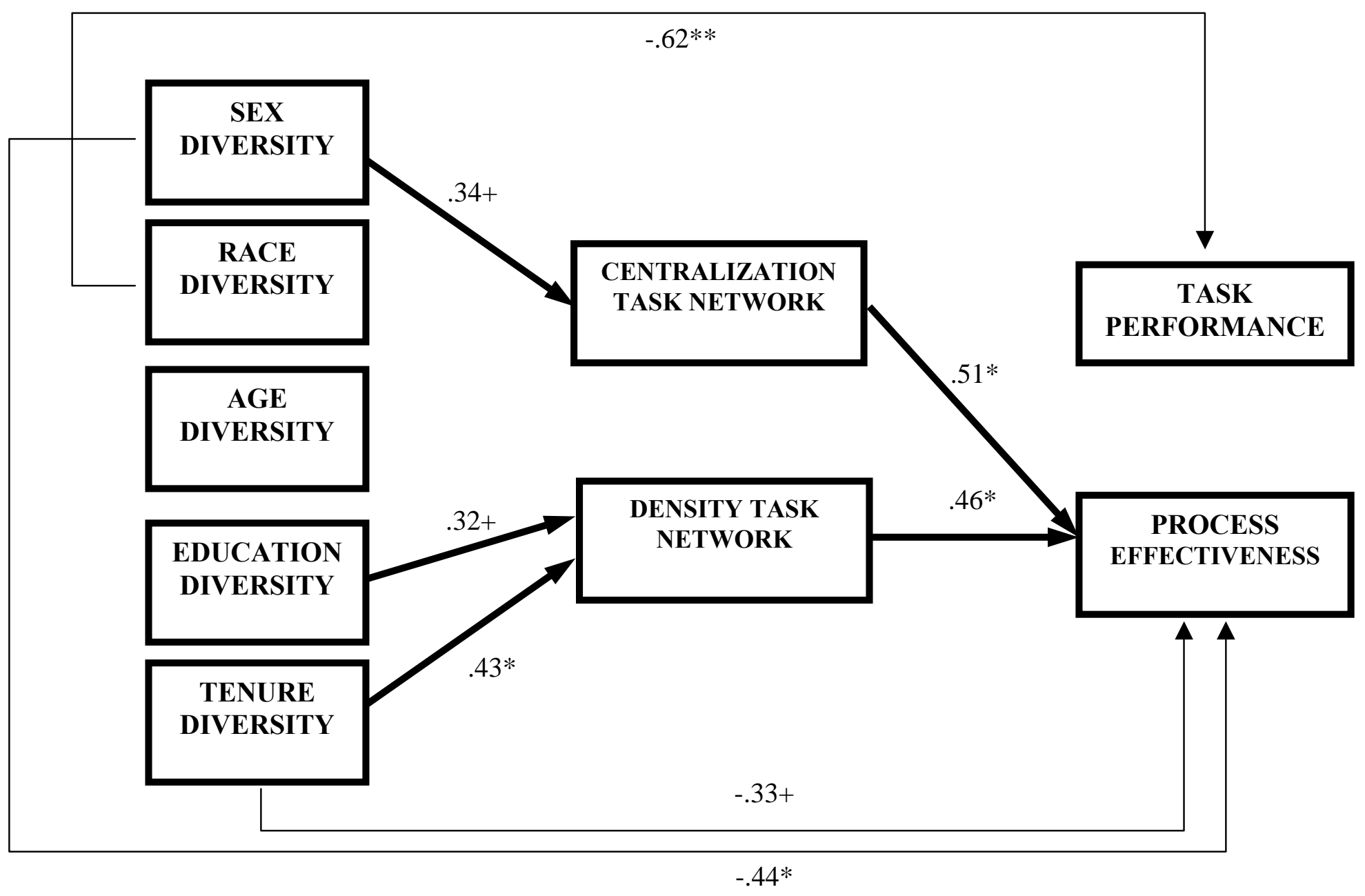


NOTAS

בx


NOTAS

בx

